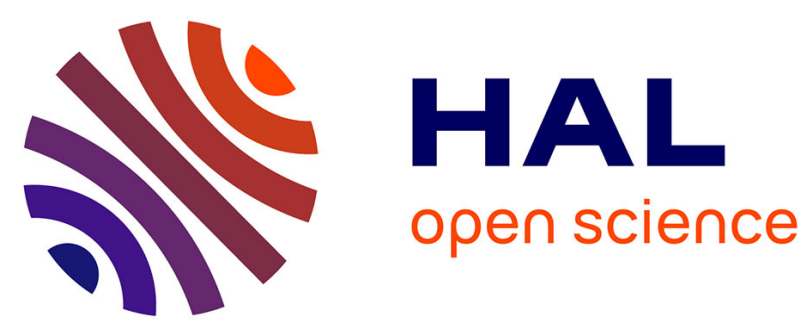

\title{
A comprehensive, genus-level time-calibrated phylogeny of the tree flora of Mediterranean Europe and an assessment of its vulnerability
}

Marwan Cheikh Albassatneh, Marcial Escudero, Loïc Ponger, Anne-Christine Monnet, Juan Arroyo, Toni Nikolic, Gianluigi Bacchetta, Francesca Bagnoli, Panayotis Dimopoulos, Agathe Leriche, et al.

\section{To cite this version:}

Marwan Cheikh Albassatneh, Marcial Escudero, Loïc Ponger, Anne-Christine Monnet, Juan Arroyo, et al.. A comprehensive, genus-level time-calibrated phylogeny of the tree flora of Mediterranean Europe and an assessment of its vulnerability. Botany Letters, 2020, 167 (2), pp.276-289. 10.1080/23818107.2019.1684360 . hal-02433733

\section{HAL Id: hal-02433733 \\ https://hal-amu.archives-ouvertes.fr/hal-02433733}

Submitted on 9 Jan 2020

HAL is a multi-disciplinary open access archive for the deposit and dissemination of scientific research documents, whether they are published or not. The documents may come from teaching and research institutions in France or abroad, or from public or private research centers.
L'archive ouverte pluridisciplinaire HAL, est destinée au dépôt et à la diffusion de documents scientifiques de niveau recherche, publiés ou non, émanant des établissements d'enseignement et de recherche français ou étrangers, des laboratoires publics ou privés. 
ARTICLE

\title{
A comprehensive, genus-level time-calibrated phylogeny of the tree flora of Mediterranean Europe and an assessment of its vulnerability
}

\author{
Marwan Cheikh Albassatneh ${ }^{\mathrm{a}, \mathrm{b} *}$, Marcial Escuderoc*, Loic Ponger ${ }^{\mathrm{d} *}$, Anne-Christine Monnet ${ }^{\mathrm{a}, \mathrm{d}}$, Juan Arroyoc, \\ Toni Nikolic ${ }^{e}$, Gianluigi Bacchetta ${ }^{f}{ }^{f}$, Francesca Bagnolig ${ }^{\text {, Panayotis Dimopoulos }}{ }^{\mathrm{h}}$ Agathe Leriche $^{\mathrm{a}}$,

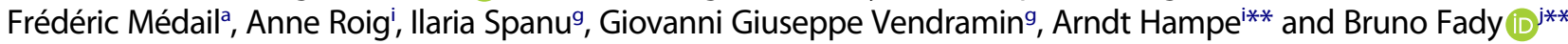 \\ aAix Marseille Univ, Avignon Université, CNRS, IRD, IMBE, Marseille, France; 'bnstitute of Ecology and Environmental Sciences, Sorbonne \\ University, Paris, France; 'Department of Plant Biology and Ecology, University of Seville, Seville, Spain; ${ }^{d}$ MNHN, Paris, France; 'Department \\ of Botany, Faculty of Science, University of Zagreb, Zagreb, Croatia; 'Department of Life and Environment Sciences, University of Cagliari, \\ Cagliari, Italy; ${ }^{9} \mathrm{CNR}$, IBBR, Florence, Italy; ${ }^{h}$ School of Natural Sciences, University of Patras, Rio, Greece; 'BIOGECO, INRA, Bordeaux \\ University, Cestas, France; INRA, UR629, Ecology of Mediterranean Forests (URFM), Avignon, France
}

\begin{abstract}
We produced the first time-calibrated phylogeny of all 64 native tree genera occurring on the European side of the Mediterranean Basin. This phylogeny is based on 3 plastid DNA sequences $(r b c \mathrm{~L}$ matK and $t r n \mathrm{H}-p s b \mathrm{~A}), 4$ recognized fossil dates and 10 secondary calibrations. Based on the inferred topology, we then tested whether the investigated tree flora exhibits phylogenetic clustering in both life-history traits known to influence reproduction and species' vulnerability to extinction. Our topology and the estimated dates mostly conform to published partial phylogenies and are highly congruent with the Angiosperm Phylogeny Group classification except for some minor incongruences including the still debated phylogenetic position of Magnoliids. The four strictly endemic genera of the Mediterranean Basin (Chamaerops, Phillyrea, Spartium and Tetraclinis) all showed emergence dates (11-72 Ma) long before the onset of the Mediterranean climate. We did not find any imprints of phylogenetic sorting processes on the life-history traits we studied, except for the mode of seed dispersal, which showed a clustered distribution across our topology. The presence of species at risk of potential extinction within a given genus was randomly distributed along the phylogenetic tree. Species with deficient data were significantly nested within a few of the most recently evolved angiosperm genera. Our analysis closes knowledge gaps and provides a valuable basis for studying the biogeographical and ecological processes that have generated the Mediterranean tree flora. It can also inform conservation planning strategies that aim at broadening traditional taxonomy-focused perspectives with components of evolutionary history and phylogenetic singularity.
\end{abstract}

ARTICLE HISTORY

Received 4 July 2019

Accepted 21 October 2019

KEYWORDS

Woody plants; molecular evolution; plastid DNA; conservation; mating system; Bayesian; Maximum likelihood

\section{Introduction}

The Mediterranean climate biome comprises several major hotspots of plant biodiversity that jointly harbor $20 \%$ of the world's floristic richness on only $2 \%$ of its terrestrial surface (Médail and Quézel 1997). Comprehensive biome-wide phylogenetic surveys are already available for four of the five Mediterranean climate regions of the world: South Africa (Forest et al. 2007), California (Thornhill et al. 2017; Kling et al. 2018), Chile and Australia (Morlon et al. 2011). Surprisingly, such a comprehensive phylogeny is still lacking for the Mediterranean Basin, by far the largest Mediterranean climate region of the world that accounts for ca. $80 \%$ of the global distribution of this biome. Its estimated plant richness is 25,000 species, among which 13,000 are endemics (Suc 1984; Quézel 1985).

The tree flora of the Mediterranean Basin is particularly remarkable and far more species-rich than that of temperate Europe (Quézel and Médail 2003; Montoya et al. 2007). Mediterranean Europe shelters no less than 45 endemic tree species (Médail et al. 2019), for which scarcely any phylogenetic information is available. Trees are likely to be excellent witnesses of deep history events and the tree flora is known to be a good proxy of biodiversity in general and in the Mediterranean region (Kati et al. 2004; Thompson 2005; Petit and Hampe 2006; Conord et al. 2012).

Phylogenetic information could thus directly inform conservation strategies for regional plant diversity and endemism (Simon-Porcar et al. 2018), an urgent task in this biodiversity hotspot that has faced intense anthropogenic pressures over an extended period of time (Médail and Quézel 1997). The potential of such approaches has recently been illustrated by the publication of the phyloflora of California (Thornhill et al. 2017) that has allowed to propose the inclusion of evolutionary diversification, divergence and survival as 
conservation targets (Kling et al. 2018). Finally, although extinction risk is not an evolving trait (Grandcolas et al. 2011), ecosystem sustainability and services are at greater risk when functional traits of keystone species show a phylogenetic signal (Díaz et al. 2013). Thus, assessing the distribution of species' extinction risk along a phylogenetic tree provides increased-value information for conservation compared to taxonomically independent assessments (Forest et al. 2007; Fritz and Purvis 2010; Yessoufou et al. 2012)

Hence, a proper knowledge of the phylogenetic relationships among Mediterranean tree taxa can represent a powerful tool to better understand current patterns of forest diversity (taxonomic, phylogenetic and functional) and how they were shaped by the region's landmark Tertiary events such as the desiccation of the Mediterranean Sea during the Messinian Salinity Crisis (6-5.3 Million years ago (Ma)), the onset of the Mediterranean climate in the late Pliocene (3.2-2.8 Ma; Suc 1984). Lineage age was actually shown to account for much of the diversity of life-history traits observed in the woody flora of Andalusia in Spain (Herrera 1992). Vice versa, life-history traits related to tree reproduction and dispersal have driven differential diversification rates of tree taxa (Herrera 1992; Lavergne et al. 2013).

In this study, we provide the first time-calibrated phylogeny of all tree genera native to Mediterranean Europe based on three chloroplast DNA regions $(r b c \mathrm{~L}$, $m a t \mathrm{~K}$ and $t r n \mathrm{H}-p s b \mathrm{~A})$ that are widely used for phylogenetic studies (Kress and Erickson 2007). We discuss the topology of our comprehensive genus-level phylogeny with a particular focus on incongruences with the Angiosperm Phylogeny Group classification (APG IV, Chase et al. 2016). We have used both fossil and secondary calibrations to make sure our times estimates were congruent with previous publications (e.g. Magallón et al. 2015). We then test whether life-history traits related to mating and seed dispersal, which are usually conserved within genera, show a phylogenetic signal. As an assessment towards the conservation of this remarkable flora, we also test whether the proportion of threatened or conservation data deficient taxa per genus shows a phylogenetic signal. Our study thus integrates perspectives from plant phylogeny, evolutionary ecology and biodiversity conservation within a common analytical framework.

\section{Material \& methods}

\section{Selection of tree taxa}

The 64 study genera (Appendix S1) are reported in the most recent checklist of tree taxa native to Mediterranean Europe (Médail et al. 2019). This checklist reports 210 tree species in the north of the Mediterranean area spanning the zone comprised between Portugal and
Greece. Médail et al. (2019) define trees as plants with four main features: “(i) secondary growth; (ii) perennials (they live many years, mostly for decades or centuries); (iii) typically (at least in some environmental conditions or locations) having a single stem or trunk, growing orthotropic with monopodial or more often sympodial branching systems, and bearing lateral branches at some distance from the ground; and (iv) the height of the mature individual is at least three meters". Four of these genera (Chamaerops, Phillyrea, Spartium and Tetraclinis) are strict Mediterranean Basin endemics, while three others (Myrtus, Nerium and Ceratonia) are Tethys endemics that are also found in the IranoTuranian and Saharan biogeographic regions (Zohary and Feinbrun-Dothan 1966). Our study included all 64 genera.

\section{Acquisition of DNA sequence data}

We used sequence data from three chloroplast DNA regions commonly used for phylogenetic and taxonomic barcoding purposes (Kress and Erickson 2007) to infer phylogenetic relationships: the protein coding $r b c \mathrm{~L}$ and mat $\mathrm{K}$ genes, and the non-coding spacer $\operatorname{trn} \mathrm{H}-p s b \mathrm{~A}$. In a first step, we retrieved all available sequence data for our study taxa from NCBI (https://www.ncbi.nlm.nih.gov/ nucleotide/; accessed June 2018). We obtained a total of 1778 sequences informative for 53 genera out of 64 . We obtained plant material for the remaining species either from herbarium collections or by collecting fresh tissue in the field. We also used available herbarium material when we considered that the number of individual samples per species was too low. We gathered 873 samples that were sequenced either at INRA-URFM, Avignon (France) or at the National Research Council (IBBR-CNR), Florence (Italy). We generated new data for, respectively, 20 (for $m a t K$ ), 79 (for $r b c L$ ) and 67 (for $\operatorname{trnH}-p s b \mathrm{~A}$ ) species. Methods used for DNA isolation and Sanger sequencing are described in detail in Appendix S2.

When we could not find any sequence data or when there was no sample available corresponding to the Mediterranean species belonging to the genera of interest for our study, we searched the NCBI database again (accessed November 2018). We then selected sequence data from the closest relative to the lacking Mediterranean species to generate a genus-level sequence, using the same strategy as mentioned above. Overall, including previously published and newly created sequences, our dataset was made of a total of 2651 sequences from, respectively, 153 (for matK), 217 (for $r b c L$ ) and 179 (for $t r n H-p s b \mathrm{~A}$ ) species covering all 64 study genera.

\section{Sequence alignment and genus-level consensus}

For each species, sequences were quality checked and edited using CodonCode Aligner (CodonCode Co., 
MA, USA) to trim and remove low-quality regions. Consensus sequences were built using the IUPAC-IUB ambiguity (Tipton 1994) code when several sequences were available for a given species. A reference sequence was obtained for each genus by using the same procedure as for individuals and species (see fasta file for all consensus sequences in Appendix S3 and at http://doi.org/10.5281/zenodo.3466621 and see details of individual sequences in Appendix S4). The number of individual (mean of 13.8) and species-level (mean of 2.21) sequences used to build the genus-level consensus sequence was quite variable owing to the varied availability of sequence data (Appendix S4).

Multiple sequence alignments were built using the program MAFFT (Katoh et al. 2002) and parsed using the program Gblocks (Castresana 2000) to exclude the segments characterized by several variable positions or gaps from the final alignment. The DNA sequences of the three gene regions were concatenated into a supermatrix (McMahon and Sanderson 2006; Soltis et al. 2013) using Seaview (Gouy et al. 2010).

\section{Phylogenetic analyses}

We inferred the genus-level phylogenetic tree of our taxa adopting both a Bayesian and a Maximum Likelihood approach. First, the combined DNA sequence matrix was analyzed using the program MrBayes (Huelsenbeck and Ronquist 2001). The selection of an appropriate substitution model of sequence evolution was conducted for each of the three chloroplast DNA regions using the Bayesian information criterion (BIC) as implemented in the program JModeltest 2 (Darriba et al. 2012). The optimal models identified for MrBayes were: $G T R+I+G$ for $m a t \mathrm{~K}, \mathrm{HKY}+\mathrm{I}+\mathrm{G}$ for $r b c \mathrm{~L}$ and $\mathrm{GTR}+\mathrm{G}$ for trn $\mathrm{H}-p s b \mathrm{~A}$. The posterior distribution of trees was explored using a Markov chain Monte Carlo (MCMC) procedure. Four chains for 10 million generations each were sampled every 100 generations with the default priors and a burn-in of $25 \%$. The analysis was repeated twice to determine whether convergence was reached. Convergence of independent runs was gauged with the average standard deviations of the split frequencies, after visual inspection of the traces and the posterior distributions for the marginal log-likelihood scores of each independent run. The root of the phylogenetic tree was located at the divergence between angiosperms and gymnosperms.

Our Maximum Likelihood analysis followed the method of Felsenstein (1973) and we used the program RAxML V8 (Stamatakis 2014). The DNA sequence matrix was analyzed using the GTR + Gamma substitution model. Node support was estimated using bootstrap with 1000 replicates.

\section{Molecular dating}

The BEAST2 software platform (Bouckaert et al. 2014) was used for the molecular dating. The input files with three partitions (one for each DNA region) were created using BEAUti2 (Barido-Sottani et al. 2017). An uncorrelated relaxed clock model assuming an exponential distribution of rates was used (Drummond et al. 2006). The selection of an appropriate substitution model of sequence evolution was conducted for each of the three organelle DNA regions using the Bayesian information criterion (BIC) as implemented in the program JModeltest 2 (Darriba et al. 2012). The optimal models identified for MrBayes were: GTR $+\mathrm{I}+\mathrm{G}$ for mat $\mathrm{K}, \mathrm{HKY}$ $+\mathrm{I}+\mathrm{G}$ for $r b c \mathrm{~L}$ and $\mathrm{GTR}+\mathrm{G}$ for $t r n \mathrm{H}-p s b \mathrm{~A}$. The posterior distribution of trees was explored using a Markov chain Monte Carlo (MCMC) procedure. Concerning the clock model, we used for three chloroplast DNA regions a relaxed clock exponential. A randomly generated starting tree was used to set the tree prior. To assume a constant lineage birth rate for each branch in the tree, we used a one parameter Yule model (pure birth) (Yule 1925).

A total of 14 fossil and secondary calibration points were selected to cover the maximum time span of the phylogenetic tree (Table 1). All points were assigned an exponential prior distribution and the most recent common ancestor (MRCA) was used for offset (Ho et al. 2005).

\section{Hierarchical clustering of life-history traits and IUCN Red List categories}

For each genus, we collected information on three lifehistory traits that have been shown to influence patterns of gene flow and rates of diversification in plants (Duminil et al. 2007; Lavergne et al. 2013). These traits are (i) breeding system (three classes: hermaphroditic, unisexual-monoecious and unisexual-dioecious), (ii) pollination mode (two classes: abiotic, biotic) and (iii) seed/ fruit dispersal mode (two classes: abiotic, animal). All three life-history traits are known to be phylogenetically conserved, with a large fraction of their overall variation occurring at genus and higher levels (Herrera 1992). Accordingly, most genera were homogeneous concerning the traits we surveyed. Exceptionally (e.g., most Pinus species are dispersed by wind but some by animals), a given genus was assigned to both classes (see Appendix S5). A functional tree was then inferred using a hierarchical clustering calculated with Euclidian distance and UPGMA on the three life-history traits (Legendre and Legendre 2012).

We determined the vulnerability to extinction for every woody plant species included in the checklist of Médail et al. (2019), assigning it to one of four 
Table 1. Calibration points and age constraints used in divergence time estimations (MRCA = most recent common ancestor). Placement of the fossil or secondary calibration was assigned to the MRCA of the listed taxa.

\begin{tabular}{|c|c|c|c|c|c|c|}
\hline \multirow[b]{2}{*}{ Groups } & \multirow[b]{2}{*}{ Nodes } & \multirow[b]{2}{*}{ MRCA (Ma) } & \multicolumn{2}{|c|}{ Distribution prior (Exponential) } & \multirow[b]{2}{*}{ Estimation } & \multirow[b]{2}{*}{ Source } \\
\hline & & & Offset & M & & \\
\hline Crown & Abies/Cedrus & 128.56 & 128.56 & 2.6 & Estimated time & Kumar et al. 2017 \\
\hline Crown & Acer/Aesculus & 48.6 & 48.6 & 1.5 & Estimated time & Kumar et al. 2017 \\
\hline Crown & Chamaerops/Phoenix & 44 & 44 & 1.5 & Estimated time & Kumar et al. 2017 \\
\hline Crown & Core Eudicots & 96.2 & 96.2 & 1.5 & Fossil & Pacltová 1966, 1981 \\
\hline Crown & Cupressaceae & 70 & 70 & 2.3 & Estimated time & Lu et al. 2014 \\
\hline Stem & Ericales & 91.2 & 91.2 & 1.5 & Fossil & Nixon and Crepet 1993 \\
\hline Crown & Eudicot & 121 & 121 & 1.5 & Fossil & Doyle and Hotton 1991 \\
\hline Stem & Fabales & 66 & 66 & 1.5 & Estimated time & Kumar et al. 2017 \\
\hline Crown & Fagales & 75 & 75 & 1.5 & Estimated time & Cook and Crisp 2005 \\
\hline Crown & Lamiales & 44.3 & 44.3 & 1.5 & Fossil & Call and Dilcher 1992 \\
\hline Stem & Pinaceae & 198.4 & 198.4 & 2.3 & Estimated time & Lu et al. 2014 \\
\hline Stem & Populus/Salix & 35.5 & 35.5 & 1.5 & Estimated time & Kumar et al. 2017 \\
\hline Crown & Rosales & 82 & 82 & 1.5 & Estimated time & Bell et al. 2010 \\
\hline Stem & Sambucus/Lonicera & 83 & 83 & 1.5 & Estimated time & Kumar et al. 2017 \\
\hline
\end{tabular}

following IUCN Red List categories: Endangered (EN), Vulnerable (VU), Near Threatened (NT) and Data Deficient (DD) (Appendix S6). This was done by consulting the IUCN Red List of Threatened Species (https://www.iucnredlist.org/) in February 2019. To infer vulnerability at the genus level, we counted how many species within a given genus belonged to each of the four categories and used the resulting vector to build a phylogenetic tree adopting the same strategy as for the life-history traits (see above).

\section{Statistical analysis}

Several statistical methods were applied to test for the clustering of the life-history trait data and the IUCN categories across our topology. For the life-history traits, we performed a Mantel test to compare distance matrices, with pairwise co-phenetic distances for the phylogenetic tree and Euclidian distances for the traits. Then, trees were compared using the topological difference metric of Penny and Hendy (1985). The relative topological difference (RTD) was calculated as the proportion of the topological difference between trees,

such as: $R T D=\frac{\text { topological difference }}{2 n-6}$,

ranging from 0 (no difference) to 1 (completely different) where $n$ is the number of genera and $2 n-6$ the maximum number of topological differences. Trees were also compared using the branch length score (BLS) of Kuhner and Felsenstein (1994), which takes branch length into account in addition to the number of branches that differ between trees (Steel and Penny 1993). The trees were always considered as unrooted.

We then computed phylogenetic signals for the life-history traits and the vulnerability categories. Because our dependent variables were scored as binary characters, we measured phylogenetic signals using Fritz and Purvis' $D$ statistic (Fritz and Purvis 2010) as implemented in the function "phylo.d" in the caper R package (Orme et al. 2013). The
$D$ statistic is based on the sum of changes in node values along the branches of a tree. It provides an estimate of phylogenetic conservatism for binary traits that can be compared either with a random shuffle of trait values at the tips of a phylogeny, or with a Brownian motion model of evolution that allows to depict evolutionary diversification processes along a topology. The $D$ statistic does not significantly differ from 1 if the observed binary trait has a random distribution across the tips of the phylogeny. Values greater than 1 indicate over dispersion and values below 1 clumping of the traits compared to the random expectation as inferred from the random shuffle. If clumping against random expectations is confirmed (i.e., $D<1$ ), one can further test whether it also persists under Brownian evolution. $D$ is 0 if the observed trait has a clumped phylogenetic distribution as if it had evolved under the Brownian motion model of evolution, and less than 0 if the binary trait is more phylogenetically conserved than the Brownian expectation. This is confirmed when $D<0$ according to the corresponding statistical test. We assessed the significance of the $D$ estimates using permutation tests with 1000 permutations, once testing against a random distribution of tip states and once against the Brownian threshold model.

All comparative analysis were performed in $\mathrm{R}$ ( $\mathrm{R}$ Core Team 2015) using packages: ape (Paradis et al. 2004), phytotools (Silsbe and Malkin 2015), picante (Kembel et al. 2010), vegan (Oksanen et al. 2012), phylobase (Hackathon et al. 2013), adephylo (Jombart et al. 2010), dendextend (Galili 2015) and ade4 (Chessel et al. 2004).

\section{Results}

The number of concatenated nucleotide sites added up to 1,759 base pairs, of which 1177 showed polymorphism. Alignment length for $m a t K$ was $777 \mathrm{bp}, 635 \mathrm{bp}$ for $r b c L$ and 338 bp for $t r n \mathrm{H}-p s b \mathrm{~A}$ (Cheikh Albassatneh et al. 2019). 


\section{Phylogenetic trees}

The Bayesian phylogenetic tree is shown in Appendix S7 Figure 1. Within gymnosperms, the Pinales were clearly separated (Posterior Probability $(\mathrm{PP})=1$ ) from the Cupressaceae and their relatives. Within angiosperms, Laurales and Arecales (monocots) formed a statistically non-significant clade $(\mathrm{PP}<0.90)$ that was sister to all eudicots $(\mathrm{PP}=1)$. Within the eudicots, most nodes received high statistical support. Proteales were sister to Pentapetalae and Buxales (PP $=0.96$ ). Buxales (monophyly supported by $\mathrm{PP}<0.90$ ) were sister to Pentapetalae (monophyly supported by PP $=1$ ). Pentapetalae comprised several major clades: (i) the order Caryophyllales represented by the genus Tamarix ( $\mathrm{PP}=1)$; (ii) the superrosids $(\mathrm{PP}=0.94)$ containing the order
Saxifragales and the rosids; and (iii) the superasterids ( $\mathrm{PP}<0.90)$. Caryophyllales, superasterids and superrosids were successive sister clades. The superrosids and superasterids (represented here only by the asterids) were also recovered in the trees $(\mathrm{PP}=0.99)$. Within the superrosids, Crossomatales were placed as sister to all fabids (although non-significantly supported, PP $<0.90$ ). Malvales and Myrtales formed a weakly supported clade $(0.90<\mathrm{PP}<1)$ that appeared as sister to Sapindales with high support $(\mathrm{PP}=1)$.

The Bayesian phylogenetic tree shown in Appendix S7 was very similar to the Maximum Likelihood tree (Appendix S8). The differences were (i) using the Bayesian method, the tree topology in the Pinaceae was organized as (Pinus, (Abies, Cedrus) $)(\mathrm{PP}=1)$,

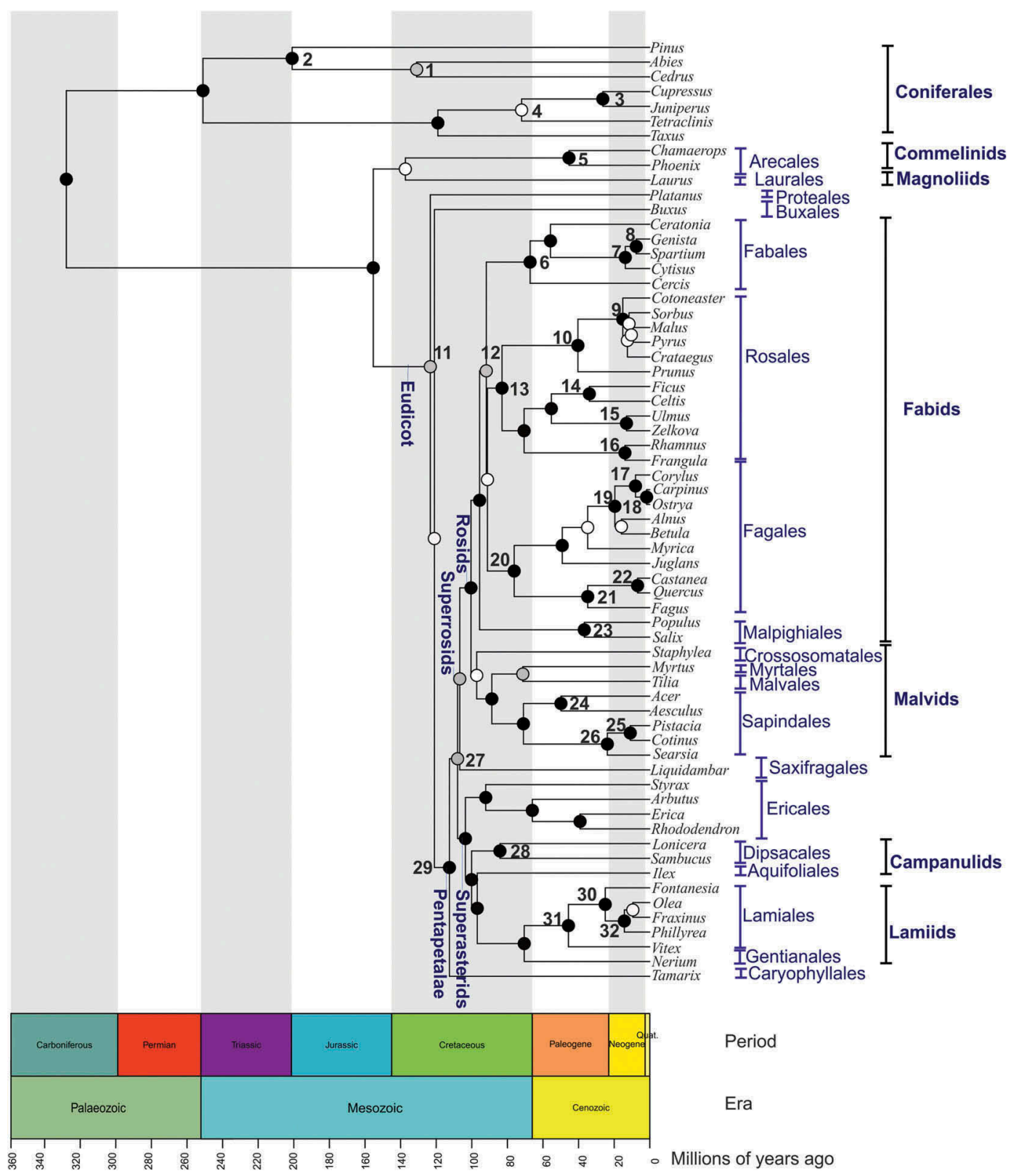

Figure 1. Maximum clade credibility chronogram of the 64 tree genera of Mediterranean Europe based on the three plastid DNA sequences matK, rbcL and trnH-psbA using the software platform BEAST2 (Bouckaert et al. 2014). Divergence time is given in million years before present. The $95 \%$ posterior density credibility intervals for node ages are indicated by blue bars. Detailed values for the labeled nodes are given in Appendix S10. 
(i.e. Pinus is paraphyletic, with the sister genera Abies and Cedrus nested within it) whereas the Maximum likelihood analysis approach inferred that it was organized as (Abies, (Pinus, Cedrus)) (Bootstrap support $(B S)=100)$, (ii) both methods found a few differences concerning support value in some clades (Appendix S9), with a higher node support on the Bayseian tree than in the Maximum Likelihood tree in several cases, (iii) Laurales were sister to eudicots in the Bayesian tree, while sister to monocots in the maximum likelihood analysis. Such clades, for which there is a phylogenetic discrepancy with the APG IV classification, are highlighted in Appendix S7 (and Appendix S8 for Maximum Likelihood approach).

\section{Diversification times}

The MrBayes and BEAST2 analyses provided highly congruent phylogenetic trees, with one major difference in composition: the BEAST2 tree (Figure 1) placed Crossosomatales, Myrtales and Malvales as successive sisters to Sapindales $(\mathrm{PP}=1)$, whereas the MrBayes tree placed Crossosomatales (represented by Staphylea) as sister clade to fabids (Figure 1)(Appendix S7).

The 95\% highest posterior density age-group estimates for the divergence of major lineages were as follows (Figure 1 and Appendix S10):

- Within gymnosperms: the Pinaceae diverged 198.40-206.45 million years ago (Ma), during the early Jurassic while the Cupressaceae diverged later, during the late Cretaceous (70.00-76.37 Ma);

- Within angiosperms, the superrosids and superasterids diverged the earliest 102.90-114.03 Ma during the Cretaceous. The split among the Fabales occurred 66.00-69.99 $\mathrm{Ma}$ at the Mesozoic Cenozoic transition while the Arecales diverged 44.00-48.10 Ma and the Lamiales 44.40-49.51 Ma during the mid-Paleogene. Within Lamiales, the group consisting of Phillyrea, Olea and Fraxinus diverged 4.41-39.60 Ma and within Fabales the group consisting of Spartium, Genista and Cytisus diverged 1.78-27.52 Ma, during the Neogene or the Paleogene. The clade consisting of Spartium and Genista diverged $0.66-15.10 \mathrm{Ma}$ during the Neogene.

The four Mediterranean Basin endemics diverged from their closest relatives between 72.3 and 11.35 Ma. Tetraclinis emerged during the late Cretaceous (node 4 in Figure 1, dated $72.3 \mathrm{Ma}$ ). This divergence time is almost twice as old as that of Chamaerops (node 5 in Figure 1) dated $45.43 \mathrm{Ma}$, during the midPaleogene. Spartium and Phillyrea (nodes 8 and 32 in Figure 1, respectively) diverged around 11 to $12 \mathrm{Ma}$ during the Neogene. The three Tethys endemics
(Ceratonia, Myrtus and Nerium) emerged at the same time or earlier than Tetraclinis, the oldest strict Mediterranean endemic genus (Figure 1).

\section{Phylogenetic signal in functional traits}

The Mantel test revealed a rather weak and marginally significant relationship between the distance matrices of phylogeny and life-history traits $(r=-0.056, P=0.09)$. The tree topologies based on the distance matrices for the phylogenetic and the life-history trait data showed moderate differences $(\mathrm{RTD}=0.472 ; \mathrm{BLS}=1.639$, Figure 2).

The measure of phylogenetic signal, $D$, and the associated statistical tests showed that our three life-history traits all showed clumped distributions with respect to fully random expectations (Table 2, Figure 3). Breeding system and pollination mode did not differ from random expectations under a Brownian model of evolution, whereas seed/fruit dispersal mode showed a significantly clumped pattern compared to the Brownian model (a trend that was more pronounced for animal dispersal than for abiotic dispersal), thus a phylogenetic signal different from that of the genera alone.

\section{IUCN Red List categories}

Endangered species occurred in $14.1 \%$ of the 64 genera $(\mathrm{N}=9)$, Vulnerable species in $14.1 \%(\mathrm{~N}=9)$, Near Threatened species in $12.5 \%(\mathrm{~N}=8)$ and Data Deficient species in $23.4 \%(\mathrm{~N}=15)$. Almost twothirds of the genera $(\mathrm{N}=41$ out of 64$)$ did not contain any species from one of the first three categories (i.e., for which an extinction risk can be assessed based on the available data). The presence of Endangered, Vulnerable and Near Threatened species within genera was distributed at random across the phylogeny, whereas Data Deficient species showed a more clustered distribution than expected under a Brownian model of evolution (Table 3, Figure 4; see also Appendix S11).

\section{Discussion}

\section{The phylogeny of the European Mediterranean} tree flora

Our phylogeny is mostly congruent with the Angiosperm Phylogeny Group classification (APG IV, Chase et al. 2016) as we found only three relatively minor topological discrepancies. First, APG IV suggests that Magnoliids and Chloranthales form a clade that is sister to a clade formed by monocots, Ceratophyllales and eudicots, whereas our tree (taking into account that we did not include Chloranthales and Ceratophyllales) suggests that monocots are sister 


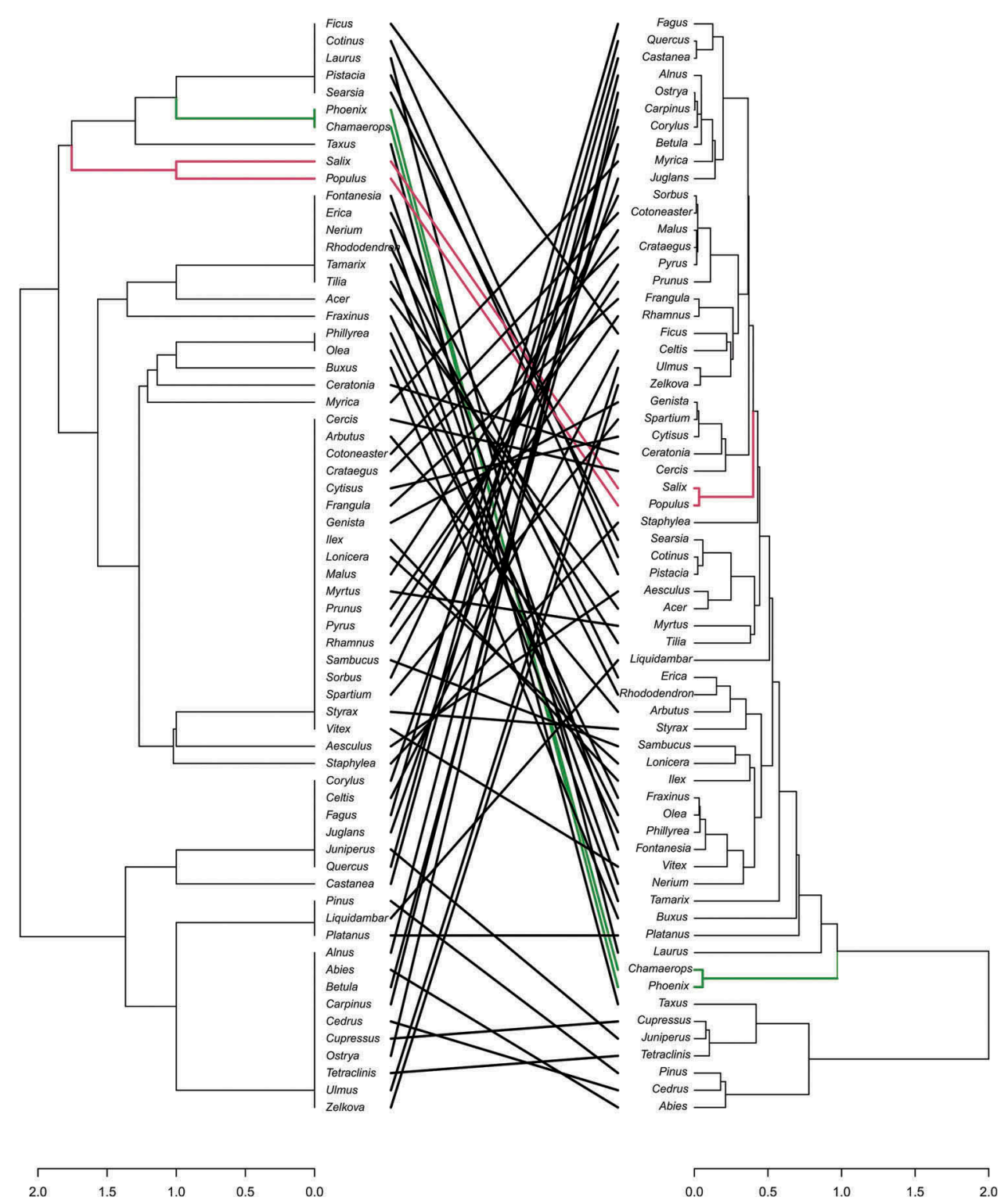

Figure 2. Tanglegram computing the phylogenetic tree (right) and the tree for life-history traits (left) of the 64 tree genera of Mediterranean Europe.

Table 2. Phylogenetic signal for functional reproductive traits in the 64 tree genera measured with the $D$ statistic (Fritz and Purvis 2010). While PE(D)Random tests for departure from a random distribution, $\mathrm{PE}(\mathrm{D})$ Brownian tests for a departure from a Brownian motion model of evolution. Statistical testing is based on 1000 permutations.

\begin{tabular}{|c|c|c|c|c|c|}
\hline \multirow[b]{2}{*}{ Binary variable } & \multicolumn{2}{|c|}{$\begin{array}{c}\text { Counts } \\
\text { of } \\
\text { states }\end{array}$} & \multirow[b]{2}{*}{$\begin{array}{c}\text { Estimated } \\
\text { D }\end{array}$} & \multirow[b]{2}{*}{$\begin{array}{c}\mathrm{PE}(\mathrm{D}) \\
\text { Random** }\end{array}$} & \multirow[b]{2}{*}{$\begin{array}{c}\mathrm{PE}(\mathrm{D}) \\
\text { Brownian** }\end{array}$} \\
\hline & 0 & 1 & & & \\
\hline Pollination: abiotic & 33 & 31 & -0.137 & 0 & 0.725 \\
\hline Pollination: biotic & 22 & 42 & -0.210 & 0 & 0.781 \\
\hline $\begin{array}{l}\text { Flower: } \\
\text { hermaphroditic }\end{array}$ & 30 & 34 & -0.196 & 0 & 0.797 \\
\hline $\begin{array}{l}\text { Flower: unisexual, } \\
\text { monoecious }\end{array}$ & 40 & 24 & 0.173 & 0 & 0.258 \\
\hline $\begin{array}{l}\text { Flower: unisexual, } \\
\text { dioecious }\end{array}$ & 54 & 10 & 0.093 & 0 & 0.434 \\
\hline Dispersal: abiotic & 39 & 25 & 0.414 & 0.003 & 0.052 \\
\hline Dispersal: animal & 20 & 44 & 0.461 & 0.004 & 0.036 \\
\hline
\end{tabular}

*Probability that $E(D)$ is significantly $<1$ and results from a random shuffle. **Probability that $E(D)$ is significantly $\neq 0$ and results from a Brownian phylogenetic structure. to the magnoliids and eudicots clades, and that magnoliids are sister to eudicots. Early diversification time discrepancies and the relationships of magnoliids with other angiosperms are currently under debate (see for example Chen et al. 2019; Coiro et al. 2019; Li et al. 2019). Our topology is supported by a recent phylogeny based on single nuclear copy genes (Zeng et al. 2014), as well as by a species-level phylogeny of the woody flora of the Spanish Sierra Nevada that used largely the same set of markers (Simon-Porcar et al. 2018).

The other two discrepancies probably arise from our relatively limited sampling: We retrieved Caryophyllales as sister to superrosids and superasterids (which is the same clade as asterids in our phylogeny), whereas APG IV suggests that Caryophyllales are included within superasterids and sister to asterids. In our phylogeny, Caryophyllales are represented by a single genus, Tamarix. Second, the Crossosomatales 


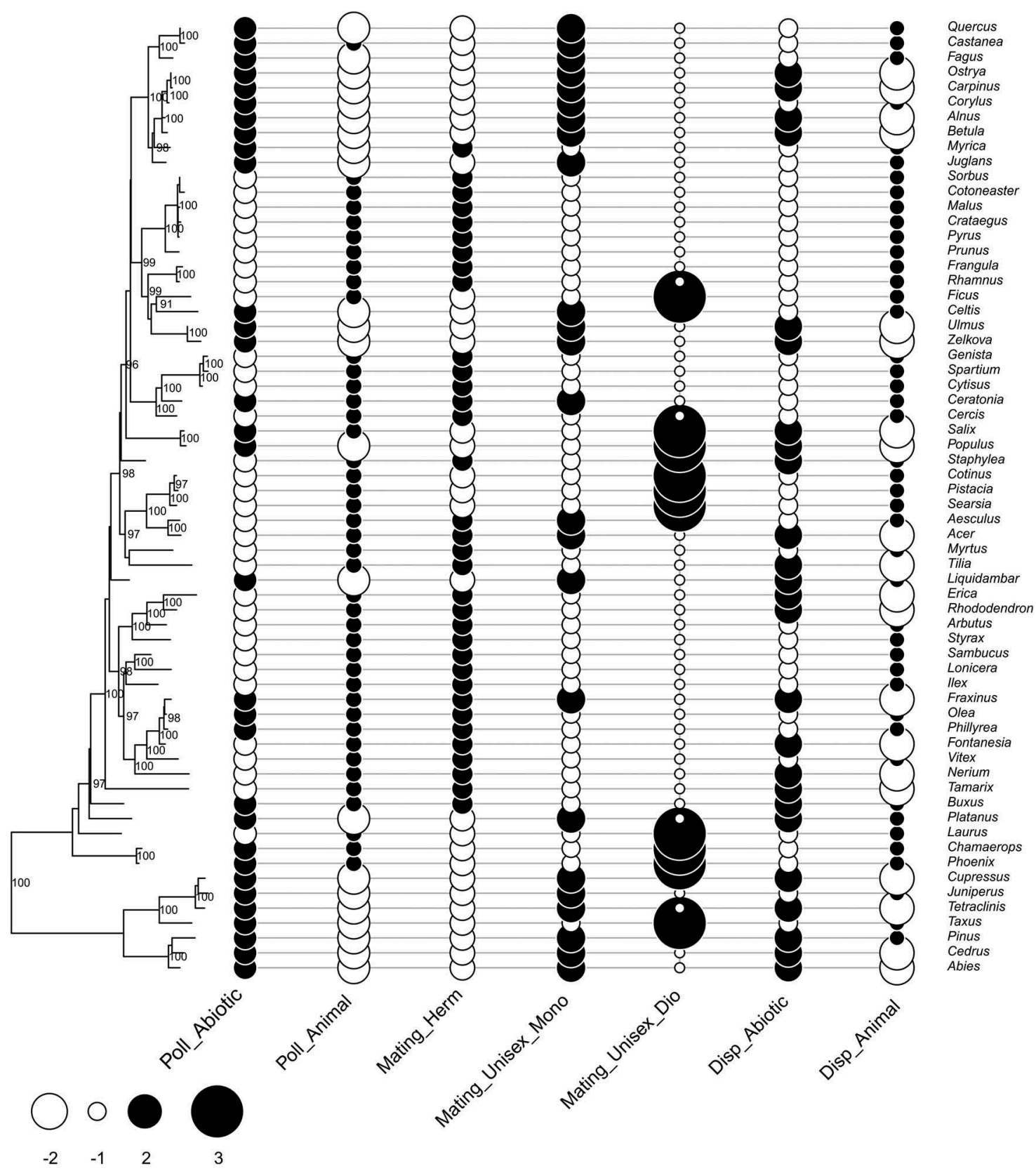

Figure 3. Standardized values (bubble size and shade) of the life-history traits along the Maximum likelihood phylogeny of the 64 tree genera of Mediterranean Europe. Codes on the X-axis are as follow: Poll_abiotic and Poll_biotic are for pollination traits (either abiotic or biotic), Mating_Herm, Mating_Unisex_Mono and Mating_Unisex_Dio are for flower types (hermaphroditic and unisexual, either monoecious or dioecious) and Disp_Abiotic and Disp_Animal are for dispersal traits (either abiotic or via an animal).

are not included within malvids but sister to fabids, albeit without clear statistical support. In our phylogeny, the Crossosomatales are represented by a single genus (Staphylea) for which one sequence out of three derives from a non-Mediterranean species.

Overall, the high congruence of our phylogeny with APG IV despite the fact that we used only three plastid DNA regions suggests that even limited numbers of markers can produce reliable results, especially when consensus sequences are carefully constructed from a certain number of input sequences (i.e., congeneric species in our case) (Forest et al. 2007; Morlon et al. 2011; Thornhill et al. 2017).

\section{Phylogeny and divergence times}

Identifying the timing of clade divergence in a reliable way is crucial for studies of evolution (Hedges and Kumar 2009; Hedges et al. 2015), and numerous phylogenetic studies have inferred divergence times of the main Spermatophyta clades during the past years, with estimates based on molecular phylogenies usually being earlier than those suggested by the fossil record (Magallón 2010). The divergence times that we inferred based on the relatively high number of calibration points (14) are generally quite congruent with previous estimates for the different Spermatophyta 
Table 3. Phylogenetic signal in different categories of conservation concern for the 64 tree genera measured with the $D$ statistic (Fritz and Purvis 2010). The counts of state column indicates the number of species that are either under one state of another of the binary variable. While $P E(D)$ Random tests for departure from a random distribution, $\mathrm{PE}(\mathrm{D})$ Brownian tests for a departure from a Brownian evolutionary motion, i.e. a clumped phylogenetic distribution. Statistical testing is based on 1000 permutations.

\begin{tabular}{|c|c|c|c|c|c|}
\hline \multirow[b]{2}{*}{ IUCN Red List category } & \multicolumn{2}{|c|}{$\begin{array}{c}\text { Counts } \\
\text { of } \\
\text { states }\end{array}$} & \multirow[b]{2}{*}{$\begin{array}{c}\text { Estimated } \\
\text { D }\end{array}$} & \multirow[b]{2}{*}{$\begin{array}{c}\mathrm{PE}(\mathrm{D}) \\
\text { random* }\end{array}$} & \multirow[b]{2}{*}{$\begin{array}{c}\mathrm{PE}(\mathrm{D}) \\
\text { Brownian }^{* *}\end{array}$} \\
\hline & 0 & 1 & & & \\
\hline Data Deficient & 49 & 15 & 0.643 & 0.042 & 0.019 \\
\hline Near Threatened & 56 & 8 & 0.865 & 0.224 & - \\
\hline Vulnerable & 55 & 9 & 1.056 & 0.592 & - \\
\hline Endangered & 55 & 9 & 0.764 & 0.115 & - \\
\hline
\end{tabular}

*Probability that $E(D)$ is significantly $<1$ and results from a random shuffle. **Probability that $E(D)$ is significantly $\neq 0$ and results from a Brownian phylogenetic structure.

-: the values of $P E(D)$ Brownian that follow a non-significant value of $P E(D)$ random were not calculated as they would have no statistical support.

groups covered by our study (Smith et al. 2010; Clarke et al. 2011; Crisp and Cook 2011; Fiz-Palacios et al. 2011; Mao et al. 2012; Magallón et al. 2013).

More specifically, we were able to confirm that the divergence of the four strict Mediterranean Basin endemics Chamaerops, Phillyrea, Spartium and Tetraclinis considerably pre-dates both the Messinian salinity crisis and the onset of the Mediterranean climate in the Late Pliocene (Suc 1984). Our estimate for the split between Chamaerops and Phoenix is in line with that proposed by Kumar et al. (2017) and that of the split between Spartium and Genista is congruent with Boatwright et al. (2008). On the contrary, our date for the split between Tetraclinis and the other Cupressaceae is slightly older than reported in a recent study focused on the Cupressaceae (Leslie et al. 2018), whereas that for Phillyrea is much younger than that reported by a study on the genus Fraxinus (Hinsinger et al. 2013). Further studies based on other sets of species and markers will be required to resolve these incongruences.

\section{Phylogenetic clustering of life-history traits linked to mating and dispersal}

All three life-history traits showed very clear signs of phylogenetic conservatism as their patterns diverged strongly from full random expectations. This conservatism is a well-known phenomenon that has repeatedly been reported in numerous studies (West-Eberhard 1989; Weller and Sakai 1999; Eriksson et al. 2000; Webb et al. 2002; Dall et al. 2012). Breeding system and mode of pollination both corresponded to a model of Brownian evolution, indicating that the phylogenetic position of taxa alone can explain the patterns of variation in these two life-history traits in the Mediterranean tree flora. In other words, we did not find any imprint of phylogenetic sorting process. On the contrary, the mode of seed/fruit dispersal showed a clustered distribution across our topology that cannot be explained by a Brownian model of evolution alone. The distribution of this life-history trait should, hence, be influenced by some ecological (such as habitat filtering or competitive exclusion) or biogeographical mechanism beyond the simple phylogenetic position of taxa (Webb et al. 2002). Such mechanisms are often very difficult to identify when the assemblage of taxa has occurred over very long periods, such as in the case of the Mediterranean Basin. However, the study of Herrera (1992) shows that historical sorting may be responsible for the clustering of traits along phylogenies, in accordance with our findings. This author identified two distinct groups of Mediterranean woody plant genera characterized by different syndromes. One group was made of relatively old ("pre-Mediterranean") genera characterized by mixed animal- and abiotic-dispersed seeds. The second group included younger ("Mediterranean") genera with mostly animal-dispersed seeds.

\section{IUCN Red List categories of extinction risk}

Contrary to life-history traits, the frequency of confirmed vulnerable species (categories EN, VU and NT) within genera was randomly distributed across the phylogeny. This finding implies that the causes of species vulnerability in the European Mediterranean tree flora are more related to global threats that concern entire forest communities and their habitats (e.g. land use change, fires, etc.) than by threats that could disproportionately affect species with certain phylogenetically conserved traits (Schachat et al. 2016). Such a trend was recently reported by Mankga and Yessoufou (2017), who found that phylogenetically closely related species of Cycads were more threatened than expected by habitat loss, over-collection, medicinal uses and reproduction failure.

Interestingly, we also found that species for which there is inadequate information to make a reliable assessment of their extinction risk (category Data Deficient) were concentrated in relatively few clades. For instance, the Fagaceae and the Rosaseae families contained several such species whereas the conifers counted very few data deficient species. One possible explanation might be differences in the conspicuousness of different species and ease of their taxonomic identification. For instance, most conifers are easier to detect and determine than some Rosaceae species that are moreover susceptible of experiencing hybridization. Such a phenomenon would be in line with observations of Arroyo (2002) who reviewed the features of Mediterranean Narcissus species in relation to their protection status and found that large-flowered species were more likely to figure in lists of protected species than small-flowered species. 


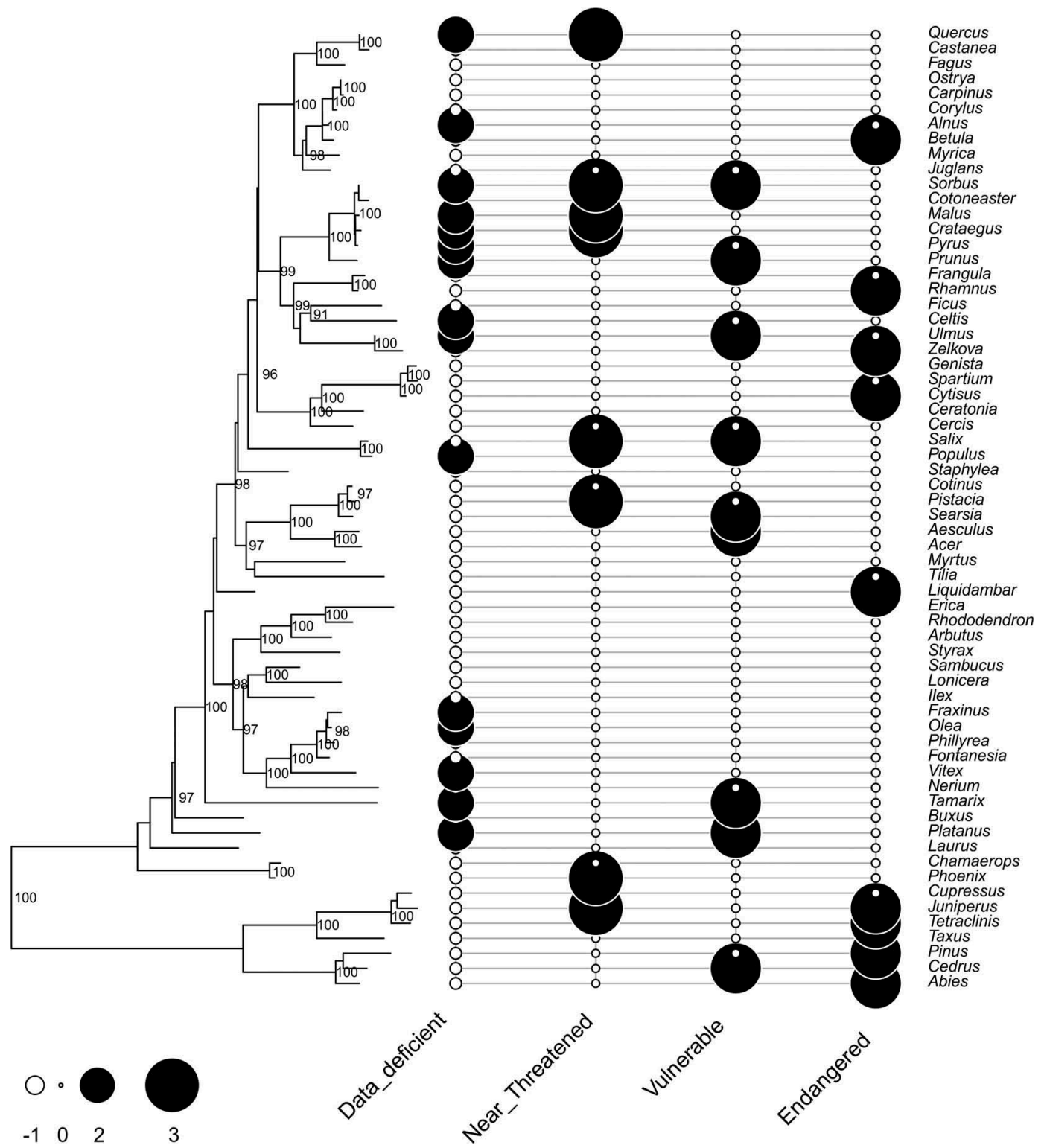

Figure 4. Standardized values (bubble size and shade) of the four IUCN Red List categories Endangered, Vulnerable, Near Threatened and Data Deficient along with the Maximum likelihood phylogeny of the 64 tree genera.

\section{Conclusions and perspectives}

Traditional biodiversity assessment studies have focused on the distribution of taxonomic richness (Ricklefs and Schluter 1993). While species identities are important for systematics and conservation, these by themselves convey little information about how species have reached their current distribution and niche and, ultimately, the coexistence patterns and phenotypes that determine the different types of plant assemblages. Historical setting of biodiversity has now expanded to include deep time evolutionary change beyond current ecological scenarios where most of diversity studies were set during the twentieth century (Ricklefs and Schluter 1993). This approach is now regularly used in community ecology and conservation science (Isaac et al. 2007; Mouquet et al. 2012; Srivastava et al. 2012; Cadotte et al. 2013; Forest et al. 2015).
Our study fits well within this context. We provide the first time-calibrated, genus-level phylogeny of the trees of the European Mediterranean region. Our molecular dating confirms the evolutionary uniqueness and conservation value of old Mediterranean endemic genera such as Tetraclinis and Chamaerops. As done by Kling et al. (2018) for a large part of the California flora, we recommend including evolutionary uniqueness as a conservation target for the tree taxa of the Mediterranean. Projected in space, phylogenetic metrics based on our phylogeny could inform where areas of high evolutionary uniqueness are located. With DNA sequencing still under way, we aim to refine the phylogeny at species level and provide metrics of evolutionary uniqueness at this taxonomic level most used in conservation planning.

Our phylogenetic tree is not fully congruent with the distribution of some life-history traits relevant for 
reproduction (and thus diversification), indicating that the loss of particular taxa would significantly impact some ecosystem functions. We suggest that evolutionary uniqueness and functional diversity should be taken together, and not one instead of the other, for deriving conservation planning strategies.

Finally, we demonstrate that conservation threats are distributed without significant phylogenetic clustering across the phylogeny of Mediterranean trees, indicating that conservation efforts should be carried out across this entire tree of life. Offsetting data deficiency, though, clearly remains an important challenge.

\section{Acknowledgments}

This study was funded by the French Foundation for Research on Biodiversity (FRB) through its Centre for Synthesis and Analysis of Biodiversity data (CESAB) program, as part of the WOODIV research project. And the OT-Med Laboratory of Excellence at Aix-Marseille University ( $\mathrm{n}^{\circ}$ ANR-11-LABX-0061). MCA acknowledges funding for his non-permanent employment from Sorbonne Université (Paris) and from the "Programme national d'aide à l'Accueil en Urgence des Scientifiques en Exil (PAUSE)" program of Collège de France.

\section{Disclosure statement}

No potential conflict of interest was reported by the authors.

\section{Funding}

This work was supported by the Aix-Marseille University [ANR-11-LABX-0061]; Foundation for Research on Biodiversity (FRB); Sorbonne Université.

\section{Notes on contributors}

Marwan Cheikh Albassatneh is assistant professor in Syria, specialized in forest ecology and management, currently with Aix-Marseille University in France.

Marcial Escudero is a postdoctoral researcher at the University of Seville (Spain), specialized in methods for the study of plant phylogeny and Mediterranean plant systems.

Loic Ponger is a researcher at the Museum National d'Histoire Naturelle in Paris (France), with a specialty in methods in phylogenetic analysis.

Anne-Christine Monnet is a postdoctoral researcher at the Museum National d'Histoire Naturelle in Paris (France), with interests in macroecology and community and population ecology.

Juan Arroyo is professor of botany at the University of Seville (Spain), specialized in Mediterranean plant diversity.

Toni Nikolic is professor of botany at the University of Zagreb (Croatia), specialized in Mediterranean plant diversity.
Gianluigi Bacchetta is professor of systematic botany at the University of Cagliari (Italy), specialized in Mediterranean plant diversity.

Francesca Bagnoli is a researcher at the CNR in Florence (Italy) and is specialized in population genetics of forest trees.

Panayotis Dimopoulos is professor of botany at the University of Patras (Greece), specialized in Mediterranean plant diversity.

Agathe Leriche is assistant professor of ecology at AixMarseille University (France), specialized in geographic information systems.

Frédéric Médail is professor of botany at Aix-Marseille University (France), specialized in Mediterranean plant diversity.

Anne Roig is an engineer at INRA in Avignon (France), specialized in molecular biology and DNA sequencing methods for Mediterranean forest trees.

Ilaria Spanu is a postdoctoral researcher at CNR in Florence (Italy), specialized in molecular biology and DNA sequencing methods for Mediterranean forest trees.

Giovanni Giuseppe Vendramin is a senior researcher at CNR in Florence (Italy), specialized in population genetics with a special interest in Mediterranean forest trees.

Arndt Hampe is a senior researcher at INRA in Bordeaux (France) with wide-ranging interests in macroecology and community and population ecology of forest trees.

Bruno Fady is a senior researcher at INRA in Avignon (France) with wide-ranging interests in the population genetics and conservation of Mediterranean forest trees.

\section{ORCID}

Gianluigi Bacchetta (D) http://orcid.org/0000-0002-17143978

Bruno Fady (D) http://orcid.org/0000-0003-2379-7617

\section{Author contribution}

BF conceived the study and wrote the paper, MCA conceived the study, performed the analyses and wrote the paper, $\mathrm{AH}$ wrote the paper, ME and LP performed the phylogenetic tree analyses, AR, IS and FB performed DNA sequencing, ACM, JA, TN, GB, FB, PD, AL, FM and GGV contributed to the writing of the manuscript. All authors revised the text and approved its final version.

\section{References}

Arroyo, J. 2002. Narcissus (Amaryllidaceae), la evolución de los polimorfismos florales y la conservación más allá de las "listas rojas". Rev Chil Hist Nat. 75:39-55. doi:10.4067/S0716-078X2002000100005.

Barido-Sottani, J, V Bošková, LD Plessis, D Kühnert, C Magnus, V Mitov, NF Müller, J PečErska, DA Rasmussen, C Zhang, et al. 2017. Taming the BEAST -a community teaching material resource for BEAST 2. Syst Biol. 67:170-174. doi:10.1093/sysbio/syx060. 
Bell, CD, DE Soltis, PS Soltis. 2010. The age and diversification of the angiosperms re-revisited. Am J Bot. 97:1296-1303. doi:10.3732/ajb.0900346.

Boatwright, JS, V Savolainen, B-E van Wyk, A Lise SchutteVlok, F Forest, M van der Bank. 2008. Systematic position of the anomalous genus Cadia and the phylogeny of the tribe Podalyrieae (Fabaceae). Syst Bot. 33:133-147. doi:10.1600/036364408783887500.

Bouckaert, R, J Heled, D Kühnert, T Vaughan, C-H Wu, D Xie, MA Suchard, A Rambaut, AJ Drummond. 2014. BEAST 2: a software platform for Bayesian evolutionary analysis. PLoS Comput Biol. 10:e1003537. doi:10.1371/ journal.pcbi.1003537.

Cadotte, M, CH Albert, SC Walker. 2013. The ecology of differences: assessing community assembly with trait and evolutionary distances. Ecol Lett. 16:1234-1244. doi:10.1111/ele.12161.

Call, VB, DL Dilcher. 1992. Investigations of angiosperms from the Eocene of southeastern North America: samaras of Fraxinus wilcoxiana Berry. Rev Palaeobot Palynol. 74:249-266. doi:10.1016/0034-6667(92)90010-E.

Castresana, J. 2000. Selection of conserved blocks from multiple alignments for their use in phylogenetic analysis. Mol Biol Evol. 17:540-552. doi:10.1093/oxfordjournals.molbev.a026334.

Chase, MW, MJM Christenhusz, MF Fay, JW Byng, WS Judd, DE Soltis, DJ Mabberley, AN Sennikov, PS Soltis, PF Stevens. 2016. An update of the Angiosperm Phylogeny Group classification for the orders and families of flowering plants: APG IV. Bot J Linn Soc. 181:1-20. doi:10.1111/boj.12385.

Cheikh Albassatneh, M, B Fady, A Roig, I Spanu, F Bagnoli, GG Vendramin. 2019. Genus level DNA sequence data for three genes (matK, rbcL, trnH-psbA) for the paper: a comprehensive, genus-level time-calibrated phylogeny of the tree flora of Mediterranean Europe and an assessment of its vulnerability [Data set]. Zenodo. doi:10.5281/ zenodo. 3466621

Chen, J, Z Hao, X Guang, C Zhao, P Wang, L Xue, Q Zhu, L Yang, Y Sheng, Y Zhou, et al. 2019. Liriodendron genome sheds light on angiosperm phylogeny and species-pair differentiation. Nat Plants. 5:18. doi:10.1038/ s41477-018-0323-6.

Chessel, D, A-B Dufour, J Thioulouse. 2004. The ade4 package I- one-table methods. R News. 4:5-10.

Clarke, JT, RCM Warnock, PCJ Donoghue. 2011. Establishing a time-scale for plant evolution. New Phytol. 192:266-301. doi:10.1111/j.1469-8137.2011.03794.x.

Coiro, M, JA Doyle, J Hilton. 2019. How deep is the conflict between molecular and fossil evidence on the age of angiosperms? New Phytol. 223:83-99. doi:10.1111/nph.15708.

Conord, C, J Gurevitch, B Fady. 2012. Large-scale longitudinal gradients of genetic diversity: a meta-analysis across six phyla in the Mediterranean basin. Ecol Evol. 2:2600-2614. doi:10.1002/ece3.350.

Cook, LG, MD Crisp. 2005. Not so ancient: the extant crown group of Nothofagus represents a post-Gondwanan radiation. Pro R Soc B Biol Sci. 272:2535-2544. doi:10.1098/rspb.2005.3219.

Crisp, MD, LG Cook. 2011. Cenozoic extinctions account for the low diversity of extant gymnosperms compared with angiosperms. New Phytol. 192:997-1009. doi:10.1111/j.1469-8137.2011.03862.x.

Dall, SRX, AM Bell, DI Bolnick, FLW Ratnieks. 2012. An evolutionary ecology of individual differences. Ecol Lett. 15:1189-1198. doi:10.1111/j.1461-0248.2012.01846.x.
Darriba, D, GL Taboada, R Doallo, D Posada. 2012 jModelTest 2: more models, new heuristics and parallel computing. Nat Methods. 9:772. doi:10.1038/nmeth.2109.

Díaz, S, A Purvis, JH Cornelissen, GM Mace, MJ Donoghue, RM Ewers, P Jordano, WD Pearse. 2013. Functional traits, the phylogeny of function, and ecosystem service vulnerability. Ecol Evol. 3:2958-2975. doi:10.1002/ ece3.601.

Doyle, JA, CL Hotton. 1991. Diversification of early angiosperm pollen in a cladistic context. In $S$ Blackmore, S H Barnes, editors. Pollen and spores: patterns of diversification. Vol. 44. Systematics Association Special Volume. Clarendon, NY: Oxford University Press; p. 169-195.

Drummond, AJ, SYW Ho, MJ Phillips,A Rambaut. 2006. Relaxed phylogenetics and dating with confidence. Plos Biol. 4(5):e88. https://doi.org/10.1371/journal.pbio. 0040088

Duminil, J, S Fineschi, A Hampe, P Jordano, D Salvini, GG Vendramin, RJ Petit. 2007. Can population genetic structure be predicted from life-history traits? Am Nat. 169:662-667. doi:10.1086/513490.

Eriksson, O, EM Friis, P Löfgren. 2000. Seed size, fruit size, and dispersal systems in angiosperms from the early cretaceous to the late tertiary. Am Nat. 156:47-58. doi: $10.1086 / 303367$.

Felsenstein, J. 1973. Maximum likelihood and minimum-steps methods for estimating evolutionary trees from data on discrete characters. Syst Zool. 22:240-249. doi:10.2307/2412304.

Fiz-Palacios, O, H Schneider, J Heinrichs, V Savolainen. 2011. Diversification of land plants: insights from a family-level phylogenetic analysis. BMC Evol Biol. 11:341. doi:10.1186/1471-2148-11-341.

Forest, F, KA Crandall, MW Chase, DP Faith. 2015. Phylogeny, extinction and conservation: embracing uncertainties in a time of urgency. Philos Trans R Soc Lond B Biol Sci. 370:20140002. doi:10.1098/rstb.2014.0002.

Forest, F, R Grenyer, M Rouget, J Davies, R Cowling, D Faith, A Balmford, JC Manning, Ş Procheş, $M$ van der Bank, et al. 2007. Preserving the evolutionary potential of floras in biodiversity hotspots. Nature. 445:757-760. doi:10.1038/nature05587.

Fritz, SA, A Purvis. 2010. Selectivity in Mammalian extinction risk and threat types: a new measure of phylogenetic signal strength in binary traits. Conserv Biol. 24:1042-1051. doi:10.1111/j.1523-1739.2010.01455.x.

Galili, T. 2015. Dendextend: An r package for visualizing. Adjusting and comparing trees of hierarchical clustering. Bioinformatics. 31(22):3718-3720. https://doi.org/10. 1093/bioinformatics/btv428

Gouy, M, S Guindon, O Gascuel. 2010. SeaView version 4 : a multiplatform graphical user interface for sequence alignment and phylogenetic tree building. Mol Biol Evol. 27:221-224. doi:10.1093/molbev/msp259.

Grandcolas, P, R Nattier, F Legendre, R Pellens. 2011. Mapping extrinsic traits such as extinction risks or modelled bioclimatic niches on phylogenies: does it make sense at all? Cladistics. 27:181-185. doi:10.1111/j.10960031.2010.00324.x.

Hackathon, R, B Bolker, M Butler, P Cowan, DD Vienne, D Eddelbuettel, $M$ Holder, T Jombart, S Kembel, F Michonneau, et al. 2013. phylobase: base package for phylogenetic structures and comparative data. $\mathrm{R}$ package version 0.6.3. http://CRAN.R-project.org/pack age $=$ phylobase. 
Hedges, S, J Marin, M Suleski, M Paymer, S Kumar. 2015. Tree of life reveals clock-like speciation and diversification. Mol Biol Evol. 32:835-845. doi:10.1093/ molbev/msv037.

Hedges, SB, S Kumar. 2009. Discovering the timetree of life. In $S$ B Hedges, $S$ Kumar, editors. The timetree of life. New York; p. 3-18.

Herrera, CM. 1992. Historical effects and sorting processes as explanations for contemporary ecological patterns: character syndromes in Mediterranean woody plants. Am Nat. 140:421-446. doi:10.1086/285420.

Hinsinger, DD, J Basak, M Gaudeul, C Cruaud, P Bertolino, N Frascaria-Lacoste, J Bousquet. 2013. The phylogeny and biogeographic history of ashes (Fraxinus, Oleaceae) highlight the roles of migration and vicariance in the diversification of temperate trees. PLoS One. 8:e80431. doi:10.1371/journal.pone.0080431.

Ho, SY, MJ Phillips, AJ Drummond, A Cooper. 2005. Accuracy of rate estimation using relaxed-clock models with a critical focus on the early metazoan radiation. Mol Biol Evol. 22:1355-1363. doi:10.1093/molbev/msi125.

Huelsenbeck, JP, F Ronquist. 2001. MRBAYES: Bayesian inference of phylogenetic trees. Bioinformatics. 17:754-755. doi:10.1093/bioinformatics/17.8.754.

Isaac, NJB, ST Turvey, B Collen, C Waterman, JEM Baillie. 2007. Mammals on the EDGE: conservation priorities based on threat and phylogeny. PLoS One. 2:e296. doi:10.1371/journal.pone.0000296.

Jombart, T, F Balloux,S Dray. 2010. Adephylo: New tools for investigating the phylogenetic signal in biological traits. Bioinformatics. 26(15):1907-1909. https://doi.org/10. 1093/bioinformatics/btq292

Kati, V, P Devillers, M Dufrene, A Legakis, D Vokou, P Lebrun. 2004. Testing the value of six taxonomic groups as biodiversity indicators at a local scale. Conserv Biol. 18:667-675. doi:10.1111/j.1523-1739.2004.00465.x.

Katoh, K, K Misawa, K Kuma, T Miyata. 2002. A novel method for rapid multiple sequence alignment based on fast Fourier transform. Nucleic Acids Res. 30:3059-3066. doi:10.1093/nar/gkf436.

Kembel, SW, PD Cowan, MR Helmus, WK Cornwell, H Morlon, DD Ackerly, SP Blomberg,CO Webb. 2010. Picante: R tools for integrating phylogenies and ecology. Bioinformatics. 26(11):1463-1464. https://doi.org/10. 1093/bioinformatics/btq166

Kling, MM, BD Mishler, AH Thornhill, BG Baldwin, DD Ackerly. 2018. Facets of phylodiversity: evolutionary diversification, divergence and survival as conservation targets. Philos Trans $\mathrm{R}$ Soc Lond B Biol Sci. 374:20170397. doi:10.1098/rstb.2017.0397.

Kress, WJ, DL Erickson. 2007. A two-locus global DNA barcode for land plants: the coding rbcL gene complements the non-coding trnH-psbA spacer region. PLoS One. 2:e508. doi:10.1371/journal.pone.0000508.

Kuhner, MK, J Felsenstein. 1994. A simulation comparison of phylogeny algorithms under equal and unequal evolutionary rates. Mol Biol Evol. 11:459-468. doi:10.1093/ oxfordjournals.molbev.a040126.

Kumar, S, G Stecher, M Suleski, S Hedges. 2017. TimeTree: a resource for timelines, timetrees, and divergence times. Mol Biol Evol. 34:1812-1819. doi:10.1093/molbev/ msx116.

Lavergne, S, A Hampe, J Arroyo. 2013. In and out of Africa: how did the Strait of Gibraltar affect plant species migration and local diversification? J Biogeogr. 40:24-36. doi:10.1111/j.1365-2699.2012.02769.x.
Legendre, P,L Legendre. 2012. Numerical ecology. 3rd. Elsevier. ISBN: 9780444538680.

Leslie, AB, J Beaulieu, G Holman, CS Campbell, W Mei, LR Raubeson, S Mathews. 2018. An overview of extant conifer evolution from the perspective of the fossil record. Am J Bot. 105:1531-1544. doi:10.1002/ajb2.1143.

Li, HT, TS Yi, LM Gao, PF Ma, T Zhang, JB Yang, M Gitzendanner, PW Fritsch, J Cai, Y Luo, et al. 2019. Origin of angiosperms and the puzzle of the Jurassic gap. Nat Plants. 5:461-470. doi:10.1038/s41477-019-0421-0.

Lu, Y, JH Ran, DM Guo, ZY Yang, XQ Wang. 2014. Phylogeny and divergence times of gymnosperms inferred from single-copy nuclear genes. PLoS One. 9: e107679. doi:10.1371/journal.pone.0107679.

Magallón, S. 2010. Using fossils to break long branches in molecular dating: a comparison of relaxed clocks applied to the origin of Angiosperms. Syst Biol. 59:384-399. doi:10.1093/sysbio/syq027.

Magallón, S, KW Hilu, D Quandt. 2013. Land plant evolutionary timeline: gene effects are secondary to fossil constraints in relaxed clock estimation of age and substitution rates. Am J Bot. 100:556-573. doi:10.3732/ ajb.1200416.

Magallón, S, S Gómez-Acevedo, LL Sánchez-Reyes, T Hernández-Hernández. 2015. A metacalibrated time-tree documents the early rise of flowering plant phylogenetic diversity. New Phytol. 207:437-453. doi:10.1111/nph.13264.

Mankga, LT, K Yessoufou. 2017. Factors driving the global decline of cycad diversity. AoB Plants. 9:plx022-plx022. doi:10.1093/aobpla/plx022.

Mao, K, RI Milne, L Zhang, Y Peng, J Liu, P Thomas, RR Mill, S Renner. 2012. Distribution of living Cupressaceae reflects the breakup of Pangea. Pro Natl Acad Sci. 109:7793. doi:10.1073/pnas.1114319109.

McMahon, MM, MJ Sanderson. 2006. Phylogenetic supermatrix analysis of GenBank sequences from 2228 Papilionoid Legumes. Syst Biol. 55:818-836. doi:10.1080/10635150600999150.

Médail, F, A-C Monnet, D Pavon, T Nikolic, P Dimopoulos, G Bacchetta, J Arroyo, Z Barina, MC Albassatneh, $G$ Domina, et al. 2019. What is a tree in the Mediterranean Basin hotspot? A critical analysis. For Ecosyst. 6:17. doi:10.1186/s40663-019-0170-6.

Médail, F, P Quézel. 1997. Hot-spots analysis for conservation of plant biodiversity in the Mediterranean Basin. Ann Mo Bot Gard. 84:112-127. doi:10.2307/2399957.

Montoya, D, MA Rodríguez, MA Zavala, BA Hawkins. 2007. Contemporary richness of holarctic trees and the historical pattern of glacial retreat. Ecography. 30:173-182. doi:10.1111/j.0906-7590.2007.04873.x.

Morlon, H, DW Schwilk, JA Bryant, PA Marquet, AG Rebelo, C Tauss, BJM Bohannan, JL Green. 2011. Spatial patterns of phylogenetic diversity. Ecol Lett. 14:141-149. doi:10.1111/j.1461-0248.2010.01563.x.

Mouquet, N, V Devictor, CN Meynard, F Munoz, L-F Bersier, J Chave, P Couteron, A Dalecky, C Fontaine, D Gravel, et al. 2012. Ecophylogenetics: advances and perspectives. Biol Rev. 87:769-785. doi:10.1111/j.1469-185X.2012.00224.x.

Nixon, K, WL Crepet. 1993. Late cretaceous fossil flowers of ericalean affinity. Am J Bot. 80:616-623. doi:10.1002/ j.1537-2197.1993.tb15230.x.

Oksanen, J, FG Blanchet, R Kindt, P Legendre, P Minchin, RB O'Hara, G Simpson, P Solymos, MHN Stevens, H Wagner. 2012. Package 'vegan'-community ecology package. 
Orme, D, RP Freckleton, GH Thomas, T Petzoldt, SA Fritz, N Isaac. 2013. CAPER: comparative analyses of phylogenetics and evolution in R. R package version 0.5, 2, 458.

Pacltová, B. 1966. Pollen grains of angiosperms in the Cenomanian Peruc Formation in Bohemia. Palaeobotanist. 15:52-54.

Pacltová, B. 1981. The evolution and distribution of Normapolles pollen during the Cenophytic. Rev Palaeobot Palynol. 35:175-208. doi:10.1016/0034-6667(81)90108-1.

Paradis, E, J Claude, K Strimmer. 2004. APE: analyses of phylogenetics and evolution in $\mathrm{R}$ language. Bioinformatics. 20:289-290. doi:10.1093/bioinformatics/btg412.

Penny, D, MD Hendy. 1985. The use of tree comparison metrics. Syst Zool. 34:75-82. doi:10.2307/2413347.

Petit, RJ, A Hampe. 2006. Some evolutionary consequences of being a tree. Annu Rev Ecol Evol Syst. 37:187-214. doi:10.1146/annurev.ecolsys.37.091305.110215.

Quézel, P. 1985. Definition of the Mediterranean region and the origin of its flora. In C Gómez-Campo, editor. Plant conservation in the Mediterranean area. Dordrecht: Dr W. Junk Publishers; p. 9-24.

Quézel, P, F Médail. 2003. Ecologie et biogéographie des forêts du bassin méditerranéen. Paris: Elsevier.

R Development Core Team. 2015. R: A language and environment for statistical computing. Vienna (Austria): R Foundation for Statistical Computing.

Ricklefs, RE, D Schluter. 1993. Species diversity in ecological communities: historical and geographical perspectives. Chicago (IL): University of Chicago Press.

Schachat, SR, DG Mulcahy, IIIJR Mendelson. 2016. Conservation threats and the phylogenetic utility of IUCN Red List rankings in Incilius toads. Conserv Biol. 30:72-81. doi:10.1111/cobi.12567.

Silsbe, GM, SY Malkin. 2015. Phytotools: phytoplankton production tools. An R package available on CRAN. https://cran. r-project.org/web/packages/phytotools/index.html.

Simon-Porcar, V, M Escudero, L Navarro, A de Castro, J Lorite, R Molina-Venegas, J Arroyo. 2018. Using floristics, modern systematics and phylogenetics for disentangling biodiversity hotspots across scales: a Mediterranean case study. Plant Biosyst. 152:1293-1310. doi:10.1080/ 11263504.2018.1445131.

Smith, SA, JM Beaulieu, MJ Donoghue. 2010. An uncorrelated relaxed-clock analysis suggests an earlier origin for flowering plants. Pro Natl Acad Sci. 107:5897. doi:10.1073/pnas.1001225107.

Soltis, DE, ME Mort, M Latvis, EV Mavrodiev, BC O’Meara, PS Soltis, JG Burleigh, R Rubio de Casas. 2013. Phylogenetic relationships and character evolution analysis of Saxifragales using a supermatrix approach. Am J Bot. 100:916-929. doi:10.3732/ajb.1300044.
Srivastava, DS, MW Cadotte, AAM MacDonald, RG Marushia, N Mirotchnick. 2012. Phylogenetic diversity and the functioning of ecosystems. Ecol Lett. 15:637-648. doi:10.1111/j.1461-0248.2012.01795.x.

Stamatakis, A. 2014. RAxML version 8: a tool for phylogenetic analysis and post-analysis of large phylogenies. Bioinformatics. 30:1312-1313. doi:10.1093/bioinformatics/ btu033.

Steel, MA, D Penny. 1993. Distributions of tree comparison metrics: some new results. Syst Biol. 42:126-141. doi:10.1093/sysbio/42.2.126.

Suc, JP. 1984. Origin and evolution of the Mediterranean vegetation and climate in Europe. Nature. 307:429-432. doi:10.1038/307429a0.

Thompson, J. 2005. Plant evolution in the Mediterranean. New York (NY): Oxford University Press.

Thornhill, AH, BG Baldwin, WA Freyman, S Nosratinia, MM Kling, N Morueta-Holme, TP Madsen, DD Ackerly, BD Mishler. 2017. Spatial phylogenetics of the native California flora. BMC Biol. 15:1-18. doi:10.1186/s12915017-0435-x.

Tipton, KF. 1994. Nomenclature Committee of the International Union of Biochemistry and Molecular Biology (NC-IUBMB). Enzyme nomenclature. Recommendations 1992. Supplement: corrections and additions. Eu J Biochem. 1:223.

Webb, CO, DD Ackerly, MA McPeek, MJ Donoghue. 2002. Phylogenies and community ecology. Annu Rev Ecol Syst. 33:475-505. doi:10.1146/annurev.ecolsys.33.010802.150448.

Weller, SG, AK Sakai. 1999. Using phylogenetic approaches for the analysis of plant breeding system evolution. Annu Rev Ecol Syst. 30:167-199. doi:10.1146/annurev. ecolsys.30.1.167.

West-Eberhard, MJ. 1989. Phenotypic plasticity and the origins of diversity. Annu Rev Ecol Syst. 20:249-278. doi:10.1146/annurev.es.20.110189.001341.

Yessoufou, K, BH Daru, TJ Davies. 2012. Phylogenetic patterns of extinction risk in the eastern arc ecosystems, an African biodiversity hotspot. PLoS One. 7:e47082. doi:10.1371/journal.pone.0047082.

Yule, GU. 1925. A mathematical theory of evolution, based on the conclusions of Dr. J. C. Willis, F.R.S. Philos Trans R Soc Lond B Biol Sci. 213:21-87. doi:10.1098/ rstb.1925.0002.

Zeng, L, Q Zhang, R Sun, H Kong, N Zhang, H Ma. 2014. Resolution of deep angiosperm phylogeny using conserved nuclear genes and estimates of early divergence times. Nat Commun. 5:4956. doi:10.1038/ncomms5956.

Zohary, M, N Feinbrun-Dothan. 1966. Flora palaestina. Jerusalem: Israel Academy of Sciences and Humanities ed. 